\title{
Study of pyruvate kinase activity in human astrocytomas - Alanine-inhibition test revisted
}

\author{
V. K. Javalkar, K. Y. Vinod ${ }^{1}$, S. Sharada ${ }^{1}$, B. A. Chandramouli, M. N. Subhash ${ }^{1}$, V. R. Kolluri \\ Departments of Neurosurgery and ${ }^{1}$ Neurochemistry, National Institute of Mental Health and Neurosciences, Bangalore, India
}

Address for correspondence:

Dr. M. N. Subhash,

Department of Neurochemistry,

NIM HANS, Hosur Road,

Bangalore - 560 029, India.

E-mail: subhash@ nimhans.kar.nic.in

DOI: $10.4103 / 0028-3886.51281$

\begin{abstract}
Background: Recent studies have confirmed that alterations in the isoenzyme of pyruvate kinase (PK) provide tumor cells with selective growth advantage. Aims: Our aim was to establish the mean activity of the enzyme PK in human astrocytomas and to look for any trends in the activity with relation to histological grade. Materials and Methods: The PK (EC 2.7. 1.40) activity was measured in the tumor homogenate by spectrophotometric rate determination. $\triangle$ Absorbance at $340 \mathrm{~nm}\left(\mathrm{~A}_{340 \mathrm{~nm}}\right)$ per minute was obtained using the maximal linear rate for both the test and the blank. Enzyme activity was estimated in the presence and absence of amino acid alanine. Results: The mean PK level in astrocytomas was $3.5 \pm 2.0 \mathrm{mmol} / \mathrm{min} / \mathrm{mg}$ protein, which was significantly higher $(24 \% ; P<0.00 \mathrm{l})$ when compared to $2.8 \pm 0.3 \mathrm{mmol} / \mathrm{min} / \mathrm{mg}$ protein in control brain. Highest PK activity was noted in grade 2 astrocytomas. In controls there was no change in PK activity in the presence of alanine. In grade 2 astrocytomas there was 7\% decrease in mean PK activity in the presence of alanine, this difference in grade 3 astrocytomas was $33 \%$ and in grade 4 astrocytomas it was $61 \%$. As the tumors were becoming malignant there was a graded increase in the levels of PK inhibition. Conclusions: Mean PK activity was significantly higher in astrocytomas. There was a graded increase in level of PK inhibition as the tumors were becoming more malignant.
\end{abstract}

Key words: Alanine inhibition, astrocytomas, human brain, isozymes, pyruvate kinase

\section{Introduction}

Recent studies have confirmed that alterations in the isoenzyme of pyruvate kinase (PK) provide tumor cells with selective growth advantage. ${ }^{[1]}$ There are at least three isozymes of mammalian PK and in primary human brain tumors a shift occurs in the synthesis of M-type toward K-type. Isoenzyme shift can be documented with alanine-inhibition test as proposed initially by Van Veelen. ${ }^{[2]}$ Most of the previous studies were concerned regarding PK inhibition. In this paper not only did we study PK inhibition but we also established the mean PK activity in astrocytomas.

\section{Materials and Methods}

\section{Subjects, tissue collection}

The institutional ethics committee for human studies approved this study. A total number of 64 biopsy samples were analyzed. PK inhibition was studied in the presence of amino acid alanine. The study material included 53 histologically proven astrocytomas and 11 control samples. Control brain samples were obtained from temporal lobe specimens of patients who underwent temporal lobectomy and amygdalohippocampectomy for refractory epilepsy. Childhood tumors and other tumors were excluded from the study. The case material was initially selected on the basis of CT and MRI features. The tumor tissue was collected from the most representative part of the lesion during surgery. We tried to take fleshy bits of tumors when samples were biopsied and necrotic material was avoided as much as possible. A part of it was sent for histology and the remaining bit was stored at $-70^{\circ} \mathrm{C}$. PK activity was estimated only in those samples that were histologically proven to be astrocytomas. Astrocytomas were graded according to St. Anne-Mayo grading system. ${ }^{[3]}$ SPSS software version 7.5 was used for statistical analysis. 


\section{Tissue homogenate}

Tumor and control brain tissues $(\sim 0.5 \mathrm{~g})$ were homogenized in 10 volumes of ice-cold $50 \mathrm{mM}$ of Tris$\mathrm{HCl}$ buffer, $\mathrm{pH}$ 7.4. The homogenate was centrifuged at $1000 \mathrm{~g}$ for 10 minutes at $4^{\circ} \mathrm{C}$ to remove cell debris. The supernatant was collected and used for enzyme assay. The protein content of the homogenate was determined by Lowry's method ${ }^{[4]}$ using bovine albumin as the standard.

\section{Measurement of protein kinase activity}

The PK (EC 2.7.1.40) activity was measured in the tumor homogenate by spectrophotometric rate determination ${ }^{[5]}$ The reagents for the assay, phosphoenol pyruvate (PEP), nicotinamide adenine dinucleotide, reduced form (NADH), adenosine diphospahte (ADP), lactic dehydrogenase (LDH), and PK were procured from Sigma-aldrich. When the enzyme solution is mixed with the reagent there is a decrease in absorbance at $340 \mathrm{~nm}$ $\left(\mathrm{A}_{340 \mathrm{~nm}}\right) \cdot \Delta \mathrm{A}_{340 \mathrm{~nm}} /$ minute is obtained using the maximal linear rate for both the test and the blank.

Full details of the enzyme essay can be found elsewhere which is beyond the scope of this paper ${ }^{[5]}$ Inhibition of the enzyme PK was studied in the presence of amino acid alanine.

\section{Data and statistical analysis}

Statistical analysis was performed using one-way ANOVA test to compare the differences between groups and within groups. Independent sample t test was used to compare the means between two groups. All values presented are mean and SD. Statistical differences were considered to be significant at $P<0.05$. SPSS software version 7.5 was used for statistical analysis.

\section{Results}

The mean PKlevel in astrocytomas was $3.5 \pm 2.0 \mathrm{mmol} / \mathrm{min} /$ mg protein, which was significantly higher $[24 \% ; \mathrm{P}<0.001]$ when compared to $2.8 \pm 0.3 \mathrm{mmol} / \mathrm{min} / \mathrm{mg}$ protein in control brain [Table 1]. Highest PK activity was noted in grade 2 astrocytomas. In grade 3 tumors the mean PK activity was less than the control samples.

In high grade astrocytomas (grades 3 and 4) the mean PK activity was $3.07 \pm 1.59 \mathrm{mmol} / \mathrm{min} / \mathrm{mg}$ protein. The mean PK activity in high grade astrocytomas was lower than low grade astrocytomas, but it did not achieve statistical significance $(P=0.08)$.

In controls there was no change in PK activity in the presence of alanine. In grade 2 astrocytomas there was $7 \%$ decrease in mean PK activity in the presence of alanine, this difference in grade 3 astrocytomas was $33 \%$

\begin{tabular}{lccc}
\hline \multicolumn{4}{l}{ Table 1: Pyruvate kinase activity in astrocytomas } \\
\hline Grade & $n$ & Mean activity & SD \\
\hline 2 & 7 & 4.46 & 3.87 \\
3 & 17 & 2.56 & 0.94 \\
4 & 29 & 3.84 & 1.81 \\
Control & 11 & 2.8 & 0.3 \\
\hline
\end{tabular}

Activity expressed in $\mathrm{mmoles} / \mathrm{min} / \mathrm{mg}$ protein

\begin{tabular}{lcc}
\hline \multicolumn{3}{l}{ Table 2: Pyruvate kinase inhibition in astrocytomas } \\
\hline Grade & $n$ & PK inhibition (\%) \\
\hline 2 & 7 & 07 \\
3 & 17 & 33 \\
4 & 29 & 61 \\
Control & 11 & 0 \\
\hline
\end{tabular}

PK inhibition expressed in percentage

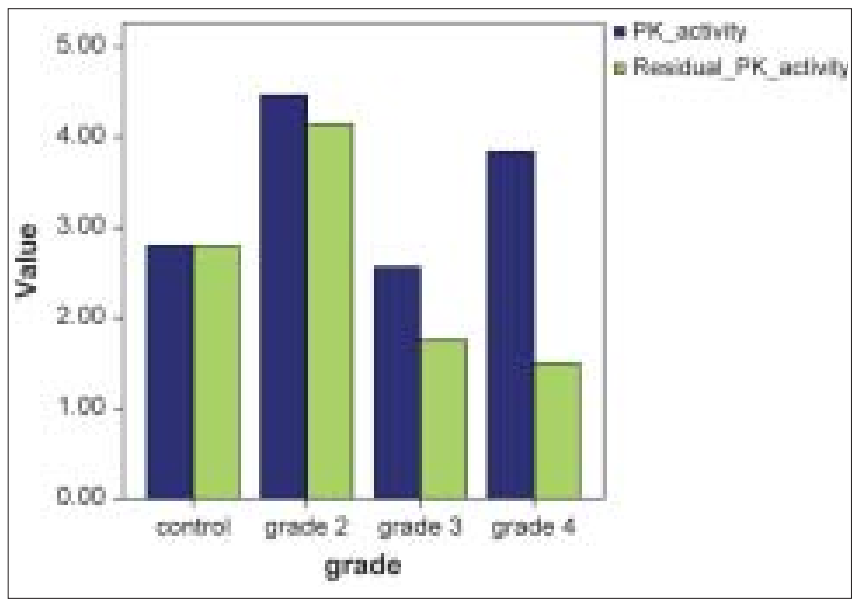

Figure 1: Comparison of pyruvate kinase activity and residual activity in astrocytomas of various grades (The mean PK (value) activity is expressed on the $\mathrm{Y}$-axis (activity expressed in $\mathrm{mmoles} / \mathrm{min} / \mathrm{mg}$ protein)

and in grade 4 astrocytomas it was $61 \%$ [Table 2]. As the tumors were becoming malignant there was a graded increase in the levels of inhibition [Figure 1].

\section{Discussion}

Metabolism of malignant cells is different from normal cells. Malignant cells have a greater tendency to employ aerobic glycolysis ${ }^{[6,7]}$ and this will be an added advantage for them to survive. PK, the rate-limiting enzyme in glycolysis, has attracted much attention in oncology. Recent studies confirm that the changes in isoenzyme offer a selective growth advantage for tumor cells in vivo. ${ }^{[1]} \mathrm{PK}$ is a tetrameric enzyme consisting of four subunits. ${ }^{[8]}$ There are at least three mammalian isozymes of PK. These are designated as the liver (L), muscle (M), and kidney $(\mathrm{K})$ type. These isozymes not only differ in their kinetic and electrophoretic properties, but also in their sensitivity to alanine. ${ }^{[2]}$ The K-type is strongly inhibited by alanine but not the M-type. In fetal brain of 12-16 weeks, M, K, and the three hybrids can be detected. ${ }^{[9]}$ The ratio of M4 and K4 in the newborn differs from the one found in adults. In the newborn $\mathrm{K} 4$ is 
predominant as compared to the adults. It seems likely that during development of human brain the synthesis of $\mathrm{K}$ subunits is repressed, whereas the reverse is found for the M subunit. ${ }^{[10]}$ Various other researchers also studied the isozymes of PK..$^{[11,12]}$ In this study the increased activity of PK in astrocytomas reflects the increase in the activity of glycolysis. Highest PK activity was recorded in grade 2 tumors followed by grade 4 tumors. Lowest activity of PK activity was noted in control samples. The dip in enzyme activity in grade 3 astrocytomas is difficult to explain.

Eventhough there was a significant increase in the activity of the enzyme in astrocytomas $(24 \%$; $P<0.001)$, we could not establish a linear relationship between mean PK activity and histological grading. Although the tumors were subdivided into high grade glioma (grades 3 and 4) and low grade glioma (grade 2), the mean activity of the PK enzyme was still high in low grade glioma and the difference did not achieve statistical significance.

Studies by Van Veelen ${ }^{[13]}$ had shown a strong correlation between both electrophoretic pattern and alanine inhibition with histological grading. In their study alanine-inhibition test had shown a linear correlation between the residual activity and histological grading. In the present study also a linear and positive correlation exists between the residual activity and the grades of astrocytomas. Studies by Mostert et al., ${ }^{[14]}$ had shown that in more malignant tumors like grade 4 astrocytomas the percentage of inhibition was higher, reaching more than $75 \%$. In the present study in grade 4 tumors the percentage of inhibition was $61 \%$ (mean value) and reaching as high as $90 \%$ in some samples. Mostert et al., ${ }^{[14]}$ had shown variable levels of inhibition in grades 2 and 3 astrocytomas. Grade 2 astrocytomas showed low to moderate level and grade 3 showed moderate to high levels of inhibition. In the present study the mean percentage of inhibition in grade 2 tumors was $7 \%, 33 \%$ in grade 3 , and $61 \%$ in grade 4 astrocytomas, showing a definite linear correlation between various grades and level of inhibition, which was not seen in the previous study. Our study was not without certain limitations. One of the drawbacks of the study was that we did not compare the results with electrophoretic pattern. In this study we focused on the mean activity of PK which was not studied earlier and to verify the reproducibility of the alanineinhibition test. The numbers of grade 2 tumors were proportionally less when compared to other grades. This is due to the fact that low grade gliomas are more common in children and we excluded them from the study. Even in adults the incidence of low grade astrocytomas is less when compared to other grades. Our samples reflect the incidence of various grades of astrocytomas in population. Further studies are needed to confirm its role in glycolysis and this enzyme could be a potential target for chemotherapy in future. In this paper we confirm the reproducibility of alanine-inhibition test and this may be used as an adjunct in grading of astrocytomas. Larger studies and also studies in other malignancies are needed to reconfirm its role as an adjunctive in grading of tumors. From this study estimation of mean PK activity might help in distinguishing high grade from low grade astrocytomas but we could not establish linear relationship between individual grades (grades 2, 3, and 4).

\section{Conclusion}

Our study demonstrated an increase in the activity of glycolytic enzyme, PK, in the astrocytomas of adults. There was a linear relationship between PK inhibition and histological grading. PK inhibition by alanine could be used to differentiate between various grades of astrocytomas. PK enzyme could be a potential target for chemotherapy in future.

\section{References}

1. Christofk HR, Vander Heiden MG, Harris MH, Ramanathan A, Gerszten RE, Wei R, Fleming MD, Schreiber SL, Cantley LC. The M2 splice isoform of pyruvate kinase is important for cancer metabolism and tumour growth. Nature 2008;452:230-3.

2. van Veelen CW, Verbiest H, van Ketel BA, van der Vlist MJ, Vlug AM, Rijksen G, Staal GE. L-alpha alanine inhibition of pyruvate kinase from tumors of the human central nervous system. Cancer Res 1979;39:4263-9.

3. Daumas-Duport C, Scheithauer B, O'Fallon J, Kelly P. Grading of astrocytomas. A simple and reproducible method. Cancer 1988;62:2152-65.

4. Lowry OH, Rosebrough NJ, Farr AL, Randall RJ. Protein measurement with the Folin Phenol reagent. J Biol Chem 1951;193:265-75.

5. Bergmeyer HU, Gawehn K, Grassl M (1974). In: Bergmeyer HU, editor. Methods of Enzymatic Analysis. Vol 1. $2^{\text {nd }}$ ed. New York, NY: Academic press, Inc; 1974. p. 509-10.

6. Sherwin AL, LeBlanc FE, McCann WP. Altered LDH isoenzymes in brain tumors. Arch Neurol 1968;18:311-5.

7. Subhash MN, Shankar SK, Rao BSS, Deshpande DH. Tissue lactate dehydrogenase isoenzyme activity in the differential diagnosis of tumors and other space occupying lesions of brain. Curr Sci 1981;50:868-70.

8. Townes PL. Electrophoresis of human pyruvate kinase. Lancet 1968;1:920-1.

9. van Veelen CW, Verbiest H, Zülch KJ, van Ketel B, van der Vlist MJ, Vlug AM, et al. Pyruvate kinase in human brain tumors. Its significance in the treatment of gliomas. Acta Neurochir (Wien) 1982;61:145-59.

10. van Veelen CW, Verbiest H, Vlug AM, Rijksen G, Staal GE. Isozymes of pyruvate kinase from human brain, meningiomas, and malignant gliomas. Cancer Res 1978;38:4681-7.

11. Cardenas JM, Dyson RD. Mammalian pyruvate kinase hybrid isozymes: Tissue distribution and physiological significance. J Exp Zool 1978;204:361-7.

12. Marie J, Kahn A, Boivin P. Pyruvate kinase isozymes in man. I. M type isozymes in adult and foetal tissues, electrofocusing and immunological studies. Hum Genet 28;31:35-45.

13. van Veelen CW, Rijksen G, Van Ketel BA, Staal GE. The pyruvate kinase isoenzyme shift in human gliomas: A potential marker in the treatment of gliomas. Br J Neurosurg 1988;2:257-63.

14. Mostert HW, de Both NJ, Rhijnsburger EH, Mackay WM, van den Berge JH, Stefanko SZ. Pyruvate kinase inhibition in the diagnosis of gliomas with an intermediate degree of malignancy. Acta Neuropathol 1986;70:296-301.

Accepted on 12-03-2009

Source of Support: Nil, Conflict of Interest: None declared. 